\title{
Innovation of Curriculum Planning in Accordance with CDIO Standards at Ho Chi Minh City University of Transport
}

\author{
Vu Thi Lan Anh, and To My Vien
}

\begin{abstract}
The CDIO initiative provides an integral approach including CDIO frameworks and CDIO standards in hopes of realizing students' learning purposes and of figuring out learning experiences to meet output-standard based education and training. Many Vietnamese universities have become pilot places of CDIO implementation as a main curriculum development not only to satisfy social requirements and international standards, but also to boost creativeness and stimulate new assessment methods and improvements for the curricular. Due to requirements of all-sided and basic innovation of tertiary education ratified by Vietnamese Party and Government (phase 2010-2020), the CDIO implementation is considered as an indispensability in $\mathrm{Ho}$ Chi Minh City University of Transport. The paper is aimed to clarify the processes and procedures to develop curricular so as to meet social demands and international standards. This paper also mentions the principles to introduce this curriculum innovation to university educational institutions of Vietnam once the CDIO approach is put into application and implemented.
\end{abstract}

Index Terms - CDIO; Curricular; Assessment Methods; Innovation; International Standards.

\section{INTRODUCTION}

The development trend of the current industries is computerization from the stage of material management to the process of production preparation, production planning, production and product quality management with automation and increased flexibility. That is to say, the flexible systems of production are controlled via computers [1]. These technological devices should be the combination and integration of the mechanic and electronic branches with microprocessors, smart sensors and user-friendly interface [2].

The reality requires us to be urgent in training and providing engineers and technicians who are able to master specialized knowledge in order to join jobs such as designing, manufacturing, maintaining, exploiting, operating as well as improving and upgrading this automatic system [3]. It is especially crucial to make sure that the production system can be effective and reliable in the long run. In addition, we also need to pay great attention to the production capacity, maintenance and repair to make them fast and economically efficient [4]. Up to now, engineers have been able to solve only a single piece of work without close and scientific connection between work sectors. Also,

Published on September 24, 2018

Vu Thi Lan Anh and To My Vien are with Ho Chi Minh city University of Transport, Ho Chi Minh city, Vietnam. the fact is there are inadequate teams of engineers who can entirely cope with problems related to interdisciplinary mechanical engineering and automation comprehensively [5]. In addition, the use of electronic devices and processors in the industry is increasing, so designing, manufacturing, operation, maintenance and upgrading of advanced production systems requires high qualified technical staff with interdisciplinary knowledge [6], [7].

The objective of the mechanical engineering education is to make sure that graduates can use, operate and maintain the equipment of the mechanical and automatic production system [8]. The training purpose of this major is also to train them in exploring and building the software used to control automatic machines via computers and other digital devices. The other goal of the training program is how to help students become knowledgeable in designing and assembling different devices in production line systems [9], [10].

However, in Vietnam in general and in Ho Chi Minh City in particular, according to some experts, the number of universities specialized in mechanic engineering to meet recruitment demands of enterprises is still very limited. On the other hand, the number of students who choose this major is also small. As a result, this obstacle will not only impact on the training purposes of the universities but also unbalance future labor force in society later.

Ho Chi Minh City University of Transport is not an exception due to the fact that economics sectors are most chosen, while mechanical engineering sectors have attracted very little interest. In average, Ho Chi Minh University of Transport annually enrolls about 100 students majored in mechanical engineering, meanwhile this university has paid great attention to the change of learning and teaching activities of mechanical engineering to adapt to new training methods, enhance the positivity, self-study and selfapprehensibility of the students.

\section{OVERVIEW OF CURRICULUM DEVELOPMENT UNDER CDIO}

The CDIO approach was formed in 2000 and originated from a big international project of the top technical universities all over the world aimed at innovating technical education with the vision of "providing students with education following the approach 'Conceive- Design Implement - Operate' on production systems and real products [9], [11]. The CDIO is expected to train students to be able to firstly master deeper knowledge of technical field, secondly to become leading in creation and operation of new products, processes and systems; and thirdly to 
understand the importance and strategic impact of research and technological development on society [12].To achieve these goals, the CDIO Approach has designed an integrated method, namely the CDIO approach, or the CDIO model, to determine the learning needs of students for the academic curriculum and the design of learning experiences to meet this need. These two components are structurally based on the best actual situations of education including CDIO frameworks and CDIO standards. The approach brings us consistent methodologies and solutions supporting us to answer the two core questions 'what to do' and 'how to do' about matters of technical education. The first question is 'what is the level of knowledge, skills, abilities and attitudes that students should obtain after graduation?'The second question is 'what should be done to help students acquire these skills?' Together with technical programmes, the CDIO approach has been put into practice with other programmes [13]-[18]. To reach the goals 'training to meet social needs' (Ministry of Training and Education, 2008) and 'training with international standards', Ho Chi Minh City University of Transport has been carrying out a prioritized program called CDIO approach, which is considered as a standard curriculum development to satisfy social and international requirements and is believed to accelerate creativity and new assessment methods. The CDIO (Conceive- Design -Implement -Operate) is a general solution for the whole training process to enhance training quality, cope with actual demands of standard output, curriculum planning, curriculum implementation and the evaluation of the effectiveness of the training program to improve it.

It is completely essential for universities to improve and innovate training procedures, training implementation and assessment based on students' levels and skills. Therefore, we should consider it as a must to master methodologies, procedures of CDIO implementation and curriculum innovation. This surely will function as a leading orientation for universities to have plans for CDIO development and innovation.

\section{PROCEDURES OF CDIO IMPLEMENTATION}

\section{A. Output standardization for training programmes}

\section{1) Knowledge standardization}

Knowledge standardization includes the following groups of knowledge. The first is general knowledge in Hanoi National University (basic knowledge, methodologies, outlooks on life, worldviews). The second is general knowledge of different fields of study (knowledge about specific traits of training sector, and interdisciplinary knowledge). The third is the general knowledge of branches of studies (general knowledge about specific traits of training sectors). The last is groups of knowledge directly related and specific to the discipline, such as specialized and complementary knowledge, including both internship and graduation knowledge (direct core knowledge of the discipline, practice, lecture, thesis, project ...).

\section{2) Skill standardization}

Systematic thinking skills (the ability to analyze problems in a logical way and compare them with other problems and the ability to view problems in many ways); the ability to identify and analyze contexts and externalities affecting the workplace and industry (including the responsibilities of the bachelor, understanding the impact of the profession on the society and the requirements of the society, historical and cultural background, issues and values of the times, global context).

We emphasize on job skills, for example occupational reasoning skills, problem detecting and solving skills. It also includes planning ability, work arrangement, goal setting, encouragement, partner care, awareness, environment adaption, budget management, meeting management, project management, stress management, brand name promotion via the internet and use of English for specific purposes. For example, students graduated from Mechanical Engineering Department should understand the knowledge of Material Technology such as metal material, welds, nonferrous metals [11]-[16], [18]. In addition, students graduated from Marine Engine Department should understand the knowledge of Energy Management, some issues related to Diesel engine, fuel including fossil fuel and biofuels [16], [17], [19]-[24]. Besides, the knowledge of environment protection is necessary for all students after graduating the universities [15], [16], [19], [21], [22], [24][28]. The ability to reason and solve problems is also one of the skill standards consisting of figuring out, generating, generalizing, evaluating, analysing, and suggesting. The next skill is researching and discovering new knowledge together with updating knowledge, recapitulating documents, analysing and researching to develop or supplement knowledge. Systematic thinking skills mean the ability to analysize problems logically using comparison and contrast from different angles. It is also a requirement for students to recognize and analyze the background and circumambiency impacting on job foundation and career. It means students with Bachelor Degree will have to be responsible for mastering the impact of these professions on society, social demands on these professions, historical background, culture, and global background. Importantly, students should learn the skills of recognizing and analysing the inner and outer conjunctures of the work places. Skills to apply knowledge into practice (flexible and appropriate application of knowledge, skills trained with professional practice, master of science and technology and tools of work; the ability to detect and solve problems in a professional way); the ability to innovate, develop and lead change in the profession (the ability to research innovation or to innovate in professional activity or lead change, update and anticipate trends, industry development and the ability to master new technology and new and used labor tools) [9]. It is also important to mention some soft skills such as selfcontrol skills that mainly focus on lifelong self-study skills, time management, environment adaption, culture literacy, and knowledge analysis [29].

Soft skills essential for the students' learning and their future world of work consist of teamwork skills (group formation, maintenance of group activities, group development); management and leadership skills (control, assignment and evaluation of group and collective activities, development and maintenance of relationships with partners, the ability to negotiate, persuade and decide on a responsible basis. social responsibility and obedience to the law); 
communication skills (conceptual arrangement, written communication and media, presentation, communication with individuals and organizations, etc.); and communication skills in foreign languages (B1 or IELTS 4.0 for mass programmes, B2 or IELTS 5.0 for high-quality programs, C1 or IELTS 6.0 for advanced programmes and international standard programmes) and other soft skills [30].

\section{3) Morality standardization}

Students are expected to possess personal morality qualifications (willingness to cope with challenges and risks, patience, persistence, flexibility, confidence, diligence, enthusiasm, passion, independence, honesty); professional ethics (professional behavior, independence, initiative, integrity, critical thinking); and social ethics (corporate responsibility, law compliance, protection of the right, creativity and innovation). This criterion is strongly emphasized in the training of students.

It is the responsibility of all training departments and those entitled to the training results to construct, perfect and carry out the CDIO approach. They must together be aware of training periods such as teaching, learning, managing staff and students, facilities and learning environment. Therefore, to reach these goals, there must be a tight connection between the stakeholders, but we need to clarify the breakthrough, forerunners, and startup jobs.

Training by CDIO methodology requires investment and optimization of faculty, facilities, time, finance and other resources. Facilities not only include space and material used for teaching, learning and research but also a work environment that satisfies learners' learning and creativity needs and practice-based training and reality.

\section{$B$. The steps to develop and improve the training program}

The survey to collect information on the training program from related parties should be conducted simultaneously with the survey to develop the learning outcomes with the appropriate toolkit. The steps to develop and improve the training program must be uniformly directed and implemented throughout the school with the following major steps:

Step 1: The Dean sets up a team and appoints a team leader to develop a training program. The composition of the team is composed of representatives from recruiters; lecturers; managers at all levels; national and international experts in the field of training; students and alumni.

Step 2: The experts do research on the current programmes of training sectors inside and outside the school, suggest ideas and base on output standards to anticipate training frameworks of knowledge groups and subject modules. This is the product of the first draft training programmes.

Step 3: The experts discuss the design of survey questionnaires, plan of survey steps, identification of information to be collected, objects and time of survey, cost estimates of survey, conduct of surveys and adjust questionnaires to carry out surveys on relevant groups. Based on the processing of questionnaires and related information, the training program is completed to develop the second draft of training program
Step 4: The output standards for each subject are built according to the second draft training program already approved with the order as followed:

1) The Dean holds a workshop on the development of learning outcomes for the subjects in the program.

2) From the program's learning outcomes, the head of the subject prepares the output standard for each subject.

3) The Dean holds a meeting of the Academic Training Board to evaluate the course outcomes.

4) The head of the subject department adjusts the output standard according to the conclusion of the Academic Training Board.

The result of this step is the Integrated Learning Outcome in the curriculum of the proposed curriculum.

Step 5: The step is to build Skills Development Matrix about developing knowledge and skills, the training order of each subject and the sketch of knowledge and skill development. The faculty Academic Training Board determines the order in which the blocks of knowledge and subject areas are met. The course syllabus clearly describes the development of knowledge, skills and ethics through research, study in one or more subjects during a certain period or throughout the training process. The product of this step is the Matrix of Knowledge and Skill Development, which corresponds to the order of implementation of the identified subjects. The combined results of this standard matrix help to identify the sequence of development of knowledge, skills, ethical qualities, and capacity to apply knowledge into practice and as the basis for finalizing the second draft training program.

Step 6: The Deans organize intensive workshops to collect contributions from managers, scientists, experts, recruiters, lecturers, current students and alumni and to complete the training program. This is the product of the third draft training program.

Step 7: The Faculty Academic Training Board evaluates and contrasts the training curriculum with standardized output, quality assurance standards and comments on the completion of the training program corresponding to the positioning of the training product. The product of this step is a complete training program.

Step 8: The training program will be first submitted to the university and then approved and officially issued. Surely, the program will also be reviewed, adjusted, supplemented and finalized to enable the university to commit the output standards and qualities of training products to meet high social demands. The training program will be evaluated based on the criteria in terms of content adjustment and selection appropriate to training sectors from the 12 standards of CDIO. Each standard of CDIO rated at five levels, from level 0 (the lowest) to level 4 (the highest). The evaluation of each standard is regularly carried out with specific contents or standards to finish a subject, a semester, a school year and a learning program.

The evaluation of the effectiveness of the training program requires evidence of input data, processes and output data. Input data includes output standards, curriculum, syllabi, teaching methods, learning, testing, assessment, status and use of material facilities and resources. Procedures include the instructional process, the assessment, and the quality and effectiveness of the program 
itself.

Output data includes academic performance, student employment, and development, level of achievement of the entire curriculum. The collection of evidence supporting the assessment of the training program is via:

- Material related to the training program (objectives, curriculum framework, course outlines, subject platform, facilities, teaching and learning methodologies).

- Individual interviews and group interviews.

- Use of surveys and teaching records.

- Use of external evaluators and follow-up student results over time.

\section{PRINCIPLES For OPENING NeW TRAining PROGRAMS}

The opening of new training programs must meet the following requirements:

1. New majors/disciplines with high social demands must be surveyed and forecasted for human resources in short-term and long-term, with high efficiency to meet the requirements of socio-economic and social development.

2. The systematic feature and transferability must be ensured among undergraduate, master and doctoral training programs in the general development plan of branches and majors.

3. Priority should be given to building interdisciplinary and unique majors, bringing into full play the strengths of the organizations. Interconnection and transferability within institutions must be promoted. Co-operation with research institutions, enterprises and recruiters must be strengthened.

4. The new training program must be in line with development plans of branches, missions, functions and tasks associated with the implementation of the development strategy of the university. Importantly, it does not concur with the branches and majors of science and technology undertaken by other faculties in the university.

5. When proposing the opening of new training programs, the organizations must base on the lists of branches and majors approved by the State in force. If the new branches and majors are not included in the list, the scheme for opening the training program should contain the scientific part of the new training majors/disciplines; practices and training experiences of some countries in the world, accompanied by the training programs of at least two universities that have been internationally verified, and to suggest a solution for the code of the branches and majors after the pilot training period.

6. The programme should be built in accordance with output standards includes the steps as demand investigation, initiative formation, pilot implementation, mass implementation following the motto 'Conceive, Design, Implement, Operate).

7. The new training programme should be in compliance with the criteria for accreditation of training programs and conditions of quality assurance, including the professional capacity of the lecturers, the ability to supplement the sources for the whole university and each unit. This also involves the capability of exploiting the resources of enterprises, agencies, units and donors, as well as non-state budget funds and other socialization possibilities;

8. Priority should be given to opening new branches/disciplines without increasing the scale of enrollment of universities.

9. The effectiveness of international co-operation should be promoted to develop the programmes and organize training to meet international standards.

10. Vietnamese universities should be based on programmes of highly prestigious universities in the world (among the top 200 universities in the world by THES rankings, QS or equivalent), or highly acclaimed international accreditation system (the top 20 programmes in the world). Subjects should be complemented to the requirements of relevant ministries, departments and schools. The subjects and their contents should meet the requirements of socioeconomic development and be in accordance with the output standards determined by CDIO; being adjusted to the conditions of Vietnam.

11. New branches/ majors should be able to be planned and organize into the state list of training courses according to general criteria.

\section{CONCLUSION}

In the present stage, integration and globalization have become a trend of the world, which is also the time when science really becomes direct production force with great influence on all fields of life. In fact, knowledge economy plays a more outstanding role in the development of production force. Our Party claimed that 'together with science and technology, education and training are considered as top-ranking national policy so as to enhance intellectual standards of the people, training human resources and fostering talented people and therefore to create material facilities to develop our country'. In this context, education has become the leading factor to the development of economy, society, and education -training. Especially due to the fact that training to meet social demands and those of enterprises is believed to be the crucial factor with the development of economy and society, the CDIO approach is a developing approach keeping up with tendency of the world. The curriculum must be inherent in evaluating the effectiveness of higher education, contributing to improving the quality of education and training at Ho Chi Minh City University of Transport in the current trend of innovation and integration.

The CDIO approach is to standardize the development of training programs, enhance learning and teaching methodologies, improve learning environment to bring a great change about quality to Ho Chi Minh City University of Transport. Considerably, in the time of innovation and integration, the CDIO approach is definitely believed to be a necessity for Ho Chi Minh City University of Transport to develop quickly, strongly and stably and then to adapt to the process of globalization. 


\section{REFERENCES}

[1] Lee, C.S., Su, J. H., Lin, K.E., Chang, J.H., Lin, G.H., “A projectbased laboratory for learning embedded system design with industry support", IEEE Trans. Educ., 53 (2010), 173-181.

[2] K. Takemata, A. Kodaka, A. Minamide, and S. Nakamura, "Engineering project-based learning under the CDIO concept," in Proceedings of 2013 IEEE International Conference on Teaching, Assessment and Learning for Engineering (TALE), 2013, pp. 258261: IEEE.

[3] A. Kamp, "Engineering Education in the Rapidly Changing World: Rethinking the Vision for Higher engineering Education," 2016.

[4] D. Goleman and R. Boyatzis, "Emotional intelligence has 12 elements. Which do you need to work on," Harvard Business Review, vol. 84, no. 2, pp. 1-5, 2017.

[5] K. Edström, "Exploring the dual nature of engineering education: Opportunities and challenges in integrating the academic and professional aspects in the curriculum," KTH Royal Institute of Technology, 2017.

[6] R. Clark, G. Thomson, E. Kontio, J. Roslöf, and P. Steinby, "Experiences on collaborative quality enhancement using crosssparring between two universities," in The 12th International CDIO Conference, 2016, p. 38.

[7] A. Berglund et al., "The pedagogical developers initiative-changing educational practices and strengthening CDIO skills," in 11th International CDIO Conference, Chengdu, China, June 8-11 2015, 2015.

[8] A. Berglund et al., "The pedagogical developers initiativedevelopment, implementation and lessons learned from a systematic approach to faculty development," in 12th International CDIO Conference, Turku University of Applied Sciences, Turku, Finland, June 12-16, 2016, 2016, pp. 497-508: Turku University.

[9] F. Ahmed, L. F. Capretz, S. Bouktif, and P. Campbell, "Soft skills and software development: A reflection from the software industry," arXiv preprint arXiv:1507.06873, 2015.

[10] K. G. King and J. W. Herrmann, "Learning outcomes for a multidisciplinary undergraduate honors program: development, measurement, and continuous improvement," Quality Approaches in Higher Education, vol. 6, no. 1, p. 4, 2015.

[11] X. D. Pham, A. T. Hoang, D. N. Nguyen, and V. V Le, "Effect of Factors on the Hydrogen Composition in the Carburizing Process," International Journal Applied Engineering Research, vol. 12, no. 19, pp. 8238-8244, 2017.

[12] A. T. Hoang, L. H. Nguyen, and D. N. Nguyen, "A Study of Mechanical Properties and Conductivity Capability of CU-9NI-3SN ALLOY," International Journal of Applied Engineering Research, vol. 13, no. 7, pp. 5120-5126, 2018.

[13] M. K. Pham, D. N. Nguyen, and A. T. Hoang, "Influence of Vanadium Content on the Microstructure and Mechanical Properties of High-Manganese Steel," The International Journal of Mechanical and Mechatronics Engineering, vol. 18, no. 2, pp. 141-147, 2018.

[14] T. N. Le, M. K. Pham, A. T. Hoang, T. N. M. Bui, and D. N. Nguyen, "Microstructure Change For Multi-Pass Welding Between Austenitic Stainless Steel And Carbon Steel," Journal of Mechanical Engineering Research \& Developments, vol. 41, no. 2, pp. 97-102, 2018.

[15] A. T. Hoang, X. L. Bui, and X. D. Pham, "A novel investigation of oil and heavy metal adsorption capacity from as-fabricated adsorbent based on agricultural by-product and porous polymer," Energy Sources, Part A: Recovery, Utilization, and Environmental Effects, vol. 40 , no. 8 , pp. 929-939, 2018

[16] A. T. Hoang, M. M. Noor, and X. D. Pham, "Comparative Analysis on Performance and Emission Characteristic of Diesel Engine Fueled with Heated Coconut Oil and Diesel Fuel," International Journal of Automotive \& Mechanical Engineering, vol. 15, no. 1, pp. 5110-5125, 2018.

[17] A. T. Hoang, Q. V. Tran, and X. D. Pham, "Performance and Emission Characteristics of Popular 4-Stroke Motorcycle Engine in Vietnam Fuelled with Biogasoline Compared with Fossil Gasoline," International Journal of Mechanical and Mechatronics Engineering, vol. 18, no. 2, pp. 97-103, 2018.

[18] A. T. Hoang, D. N. Nguyen, and V. V. Pham, "Heat Treatment Furnace For Improving The Weld Mechanical Properties: Design and Fabrication," International Journal of Mechanical Engineering \& Technology, vol. 09, no. 06, pp. 496-502, 2018.

[19] A. T. Hoang et al., "An absorption capacity investigation of new absorbent based on polyurethane foams and rice straw for oil spil cleanup," Petroleum Science and Technology, vol. 36, no. 5, pp. 361 370, 2018.

[20] A. T. Hoang, and V. T. Nguyen, "Emission Characteristics of a Diesel Engine Fuelled with Preheated Vegetable Oil and Biodiesel," The Philippine Journal of Science, vol. 146, no. 4, pp. 475-482, 2017.

[21] A. T. Hoang, "A Design and Fabrication of Heat Exchanger for Recovering Exhaust Gas Energy from Small Diesel Engine Fueled with Preheated Bio-oils," International Journal of Applied Engineering Research, vol. 13, no. 7, pp. 5538-5545, 2018.

[22] A. T. Hoang and V. V. Pham, "Impact of Jatropha Oil on Engine Performance, Emission Characteristics, Deposit Formation, and Lubricating Oil Degradation," Combustion Science and Technology, https://doi.org/10.1080/00102202.2018.1504292.

[23] T. A. Hoang and V. Van Le, "The Performance of A Diesel Engine Fueled With Diesel Oil, Biodiesel and Preheated Coconut Oil," International Journal of Renewable Energy Development, vol. 6, no. 1, pp. 1-7, 2017.

[24] V. D. Tran, A. T. Le, V. H. Dong, and A. T. Hoang, "Methods of operating the marine engines by ultra-low sulfur fuel to aiming to satisfy MARPOLAnnex VI," Advances in Natural and Applied Sciences, vol. 11, no. 12, pp. 34-41, 2017.

[25] T. A. Hoang, N. X. Chu, and T. V. Tran, "The Environmental Pollution In Vietnam: Source, Impact And Remedies," International Journnal Science Technology Research, vol. 6, no. 2, pp. 249-253, 2017.

[26] A. T. Hoang and M. Q. Chau, "A mini review of using oleophilic skimmers for oil spill recovery," Journal of Mechanical Engineering Research \& Developments, vol. 41, no. 2, pp. 92-96, 2018.

[27] A. T. Hoang, V. V. Pham, and D. N. Nguyen, "A report of oil spill recovery technologies," International Journal of Applied Engineering Research, vol. 13, no. 7, pp. 4915-28, 2018.

[28] A. T. Hoang and D. N. Cao, "Some methods of reducing NOx components in exhaust gas," Journal of International Management Studies vol. 4, no. 5, pp. 11-18, 2017.

[29] A. Lishinski, A. Yadav, and R. Enbody, "Students' Emotional Reactions to Programming Projects in Introduction to Programming: Measurement Approach and Influence on Learning Outcomes," in Proceedings of the 2017 ACM Conference on International Computing Education Research, 2017, pp. 30-38: ACM.

[30] S. Tickoo, AutoCAD 2016: A Problem-Solving Approach, Basic and Intermediate. Cadcim Technologies, 2015. 